\title{
Efficacy of botulinum toxin type A 100 Units versus 200 units for treatment of refractory idiopathic overactive bladder
}

\author{
Osama Abdelwahab ${ }^{1}$, Hammouda Sherif ${ }^{1}$, Tark Soliman ${ }^{1}$, Ihab Elbarky ${ }^{1}$, Aly Eshazly ${ }^{1}$ \\ ${ }^{1}$ Urology department, Faculty of Medicine, Benha University, Egypt
}

\section{ABSTRACT}

Objective: To evaluate the efficacy and safety of a single intra detrusor injection of BoNTA comparing two different doses (100 U or $200 \mathrm{U}$ ) in patients with idiopathic overactive bladder.

Materials and Methods: A randomized prospective study evaluated the efficacy of BoNTA in management of refractory idiopathic overactive bladder and included 80 patients. All patients were assessed initially by taking a history, a physical examination, overactive bladder symptom score, urine analysis, routine laboratory investigations, KUB and pelviabdominal. OABSS was adjusted on all patients postoperative at 1,3,6,9 months also Urodynamic was done for all patients preoperative and postoperative at 3, 6, 9 months.

Results: The mean age was $30.22 \pm 8.37$ and $31.35 \pm 7.61$ in group I and II respectively. There was no statistically difference between both groups in all parameters all over the study except at 9 months after treatment. Hematuria was observed 6 and 9 patients in group I and II respectively. Dysuria was observed in 6 and 15 patients in group I and II respectively. UTI was detected in 3 and 7 patients in group I and II respectively.

Conclusion: A single-injection procedure of $100 \mathrm{U}$ or $200 \mathrm{U}$ BoNTA is an effective and safe treatment for patients with IOAB who failed anticholinergic regimens. OABSS and QoL were improved for 6 months; $100 \mathrm{U}$ injections seemed to have comparable results with $200 \mathrm{U}$. There was a significant difference at month 9 towards $200 \mathrm{U}$ with more incidences of adverse events.

\section{ARTICLE INFO}

Key words:

Botulinum Toxins; Therapeutics; Urinary Bladder, Overactive

Int Braz J Urol. 2015; 41: 1132-40

Submitted for publication:

August 16, 2014

Accepted after revision:

October 31, 2014

\section{INTRODUCTION}

Detrusor overactivity is defined by the presence of lower urinary tract symptoms of urgency with or without urge urinary incontinence (UUI), usually with frequency and nocturia (1). In the majority of affected patients, the cause of the detrusor overactivity is idiopathic while neurogenic detrusor overactivity occurs mainly in patients with spinal cord diseases (2). Conser- vative treatments (lifestyle modifications, pelvic floor exercises, bladder training, and anticholinergic regimens) may result in insufficient improvements and in low compliance because of bothersome adverse events (3). Intradetrusor injection of botulinum neurotoxin type A (BoNTA) is emerging as the second-line treatment for refractory $\mathrm{OAB}$ symptoms (4).

Botulinum toxin is a purified neurotoxin derived from clostridium botulinum and its 
main effect is to inhibit signal transmission at the neuromuscular junction by inhibiting the release of acetylcholine. In addition, botulinum toxin is now thought to have effects on the release of other sensory neurotransmitters such as substance P and ATP, as well as reducing the axonal expression of capsaicin and purinergic receptors (5). Many studies demonstrated significant improvements in $\mathrm{OAB}$ symptoms and QoL with BoNTA treatment but they also showed increased post void residual urine, acute urinary retention and urinary tract infections (6). There is no consensus on the dose of BoNTA or BoNTB, injection sites, and the duration between repeat injections (7). This current study aimed to evaluate the efficacy and safety of a single intra detrusor injection of BoNTA alone comparing two different doses (100 U or $200 \mathrm{U}$ ) in patients with IOAB.

\section{PATIENTS AND METHODS}

This study was a randomized prospective one evaluating the efficacy of BoNTA in management of refractory idiopathic overactive bladder (IOAB) and included 80 patients who presented to the Urology Department of Benha University Hospital from May 2011 to February 2014. An informed written consent was obtained from all patients after the study protocol was approved by the Research Ethics Committee, Faculty of Medicine, Benha University. The inclusion criteria were IOAB refractory to previous anticholinergics with different types of anticholinergic agents, either as a single drug or a combination for $>3$ months. Exclusion criteria were pregnant women, uncorrectable coagulopathies, active UTI, bladder outlet obstruction, neurogenic bladder, or having a PVR $>150 \mathrm{~mL}$ at the time of enrollment, and previous radiotherapy or antineoplastic treatment. Additional use of anticholinergics was not allowed during the study period. Patients were randomly classified into two groups I and II. They underwent intradetrusor injection of BoNTA 100 and 200 Unit respectively. All patients were assessed initially by taking a history, a physical examination, overactive bladder symptom score (OABSS)
(8) (Table 1), EuroQoL (EQ-5D) visual analogue scale (VAS) (9), measuring the patient's current health-related QoL state; both scales range from 0 to 100 (worst to best), urine analysis, routine laboratory investigations, KUB and pelviabdominal spiral CT and IVP if indicated. Urodynamic evaluation was done in the form of flowmetry and cystometry.

OABSS was developed by Homma et al. (8) which is a single symptom score that employs a self-report questionnaire. There were 4-symptoms evaluated: daytime frequency, nighttime frequency, urgency and urge incontinence for the questionnaire.

The score is the simple sum of the 4-symptom scores.

\section{Injection technique}

After dilution with 10cc saline, either 100 or 200 Units BoNTA ( Allergan ${ }^{\circledR}$, Irvine, CA, USA) were used for cystoscopic intradetrusor injection under spinal anesthesia. The injection was performed in 20 sites, using 30-degree lens and a rigid scope with a 6 Fr. injection needle without side holes (Amecath Company ${ }^{\circledR}$, Egypt).

The injection sites were determined after mapping of the bladder at the anterior, left lateral, right lateral, posterior walls and the trigone (0.5cc at each site). The injection was followed by insertion of a 16 Fr. Foley's catheter, to be removed the next morning after surgery. All patients received peri-operative I.V. antibiotics. For postoperative follow-up, all patients were assessed at 1, 3, 6, 9 months using OABSS, HRQoL as well as urodynamic study at 3, 6, 9 months.

\section{Statistical analysis}

The collected data were tabulated and analyzed using SPSS version 16 software (Spss Inc. ${ }^{\circledR}$, Chicago, ILL Company). Categorical data were presented as number and percentages while quantitative data were expressed as mean and standard deviation. Chi square test (X2) and Student " $t$ " test were used as tests of significance.

The accepted level of significance in this work was stated at $0.05(\mathrm{P}<0.05$ was considered significant). 
Table 1 - Overactive bladder symptom score.

\begin{tabular}{lcc}
\hline Question & Frequency & Score \\
\hline How many times do you typically urinate from waking in the & $\leq 7$ & 0 \\
morning until sleeping at night? & $8-14$ & 1 \\
How many times do you typically wake up to urinate from sleeping & 15 & 2 \\
at night until waking in the morning? & 1 & 1 \\
& 3 & 3 \\
How often do you have a sudden desire to urinate, which is & Not at all & 0 \\
difficult to defer? & Less than once a week & 1 \\
& Once a week or more & 2 \\
How often do you leak urine because you cannot defer the sudden & About once a day & 3 \\
desire to urinate? & $2-4$ times a day & 4 \\
& 5 times a day or more & 5 \\
\hline
\end{tabular}

Patients were instructed to circle the score that best applied to their urinary condition during the past week; the overall score was the sum of the four scores.

\section{RESULTS}

Demographic baseline values

Eighty patients (63 women and 17 men) were enrolled in the study. The participants were randomly assigned to one of the two treatment groups, receiving a BoNTA dose of either $100 \mathrm{U}$ $(n=40)$ or $200 \mathrm{U}(\mathrm{n}=40)$. The mean (standard deviation) ages were 30.22 (8.37) years for group I and 31.35 (7.61) years for group II. One patient who received $100 \mathrm{U}$ of BoNTA dropped out of the study at month 6 evaluation and another one at month 9. Two patients who received $200 \mathrm{U}$ of BoNTA dropped out of the study at month 9 evaluation. There were no statistically significant differences in baseline characteristics between two groups. There was no statistically difference between both groups in all parameters all over the study except at 9 months after treatment.

\section{EFFICACY (Table 2)}

\section{Clinical symptoms}

When comparing the mean of OABSS and HRQOL data obtained at months 1, 3, 6 and 9 after treatment to baseline data it was observed significant improvement $(\mathrm{p}<0.001)$ in both groups. The mean values of OABSS and HRQOL data at months 3,6 and 9 were significantly ameliorated $(p<0.001)$ compared to data at month 1 in both groups. Within-group I analyses at month 9 demonstrated a statistically significant amelioration $(p<0.001)$ compared to data at months 3 and 6 (Table 3 ).

\section{Urodynamic values}

Comparison of urodynamic data obtained at months 3, 6 and 9 after treatment to baseline data revealed that the mean of volume at first desire, volume at strong desire, maximal cystome- 
Table 2 - Clinical symptoms and PVR Urine Changes.

\begin{tabular}{|c|c|c|c|c|}
\hline \multirow[t]{2}{*}{ Variables } & \multicolumn{3}{|c|}{ BoNTA 100} & \multirow{2}{*}{$\begin{array}{c}\text { BoNTA } 200 \\
\text { Mean(SD) }\end{array}$} \\
\hline & $\mathrm{N}$ & Mean(SD) & $\mathrm{N}$ & \\
\hline \multicolumn{5}{|c|}{ Frequency } \\
\hline Baseline & 40 & $1.6(0.496)$ & 40 & $1.67(0.525)$ \\
\hline At $1 \mathrm{~m}$ & 40 & $0.45(0.503)^{*}$ & 40 & $0.42(0.5)^{*}$ \\
\hline At $3 \mathrm{~m}$ & 40 & $0.42(0.5)^{\star}$ & 40 & $0.33(0.474)^{*}$ \\
\hline At $6 \mathrm{~m}$ & 39 & $0.51(0.506)^{*}$ & 40 & $0.3(0.464)^{*}$ \\
\hline At $9 \mathrm{~m}$ & 38 & $1.1(0.508)^{\star} \dagger \ddagger \Delta$ & 38 & $0.32(0.471)^{\star} \#$ \\
\hline \multicolumn{5}{|l|}{ Nocturia } \\
\hline Baseline & 40 & $0.87(0.965)$ & 40 & $1.2(1.202)$ \\
\hline At $1 \mathrm{~m}$ & 40 & $0.23(0.422)^{*}$ & 40 & $0.15(0.361)^{\star}$ \\
\hline At $3 m$ & 40 & $0.13(0.334)^{*}$ & 40 & $0.13(0.334)^{*}$ \\
\hline At $6 \mathrm{~m}$ & 39 & $0.13(0.338)^{\star}$ & 40 & $0.12(0.334)^{*}$ \\
\hline At $9 \mathrm{~m}$ & 38 & $0.36(0.488)^{\star}$ & 38 & $0.13(0.342)^{\star} \#$ \\
\hline \multicolumn{5}{|l|}{ Urgency } \\
\hline Baseline & 40 & $4.7(0.464)$ & 40 & $4.67(0.474)$ \\
\hline At $1 \mathrm{~m}$ & 40 & $1.4(1.37)^{\star}$ & 40 & $1.9(1.12)^{\star}$ \\
\hline At $3 m$ & 40 & $1.07(1.163)^{*}$ & 40 & $1.45(1.131)^{*}$ \\
\hline At $6 \mathrm{~m}$ & 39 & $0.97(1.135)^{\star} \dagger$ & 40 & $1.25(1.031)^{*} \dagger$ \\
\hline At $9 \mathrm{~m}$ & 38 & $2.57(0.948)^{\star} \dagger \ddagger \Delta$ & 38 & $1.47(1.202)^{\star} \#$ \\
\hline \multicolumn{5}{|l|}{ UUI } \\
\hline Baseline & 40 & $1.67(1.899)$ & 40 & $1.8(2.002)$ \\
\hline At $1 \mathrm{~m}$ & 40 & $0.77(1.073)^{\star}$ & 40 & $0.85(1.098)^{\star}$ \\
\hline At $3 m$ & 40 & $0.65(0.975)^{*}$ & 40 & $0.65(0.948)^{\star}$ \\
\hline At $6 \mathrm{~m}$ & 39 & $0.67(0.982)^{\star}$ & 40 & $0.72(1.085)^{\star}$ \\
\hline At $9 \mathrm{~m}$ & 38 & $1.26(1.171)^{\star} \dagger \ddagger \Delta$ & 38 & $0.68(0.162)^{\star} \#$ \\
\hline \multicolumn{5}{|l|}{ PVR } \\
\hline Baseline & 40 & 25.75 (12.83) & 40 & $27.4(15.05)$ \\
\hline At $1 \mathrm{~m}$ & 40 & $40.0(21.42)^{*}$ & 40 & $47.37(11.87)^{\star}$ \\
\hline At $3 m$ & 40 & $39.23(12.48)^{*}$ & 40 & $42.00(10.05)^{\star}$ \\
\hline At $6 \mathrm{~m}$ & 39 & $38.88(12.22)^{*}$ & 40 & $41.79(10.77)^{\star}$ \\
\hline At $9 \mathrm{~m}$ & 38 & $24.21(8.58) \ddagger \Delta$ & 38 & $29.21(11.30) \ddagger \Delta \#$ \\
\hline
\end{tabular}

*significant in intragrou *significant in intragroup comparison to "before intervention"

tsignificant in comparison to "1 month later

łsignificant in intragroup comparison to "3 months later"

$\Delta$ significant in intragroup comparison to "6 months later"

\#significant in intergroup comparison.

(Paired " $\mathrm{t}$ " test was the test of significance)

(N=Number of patients, UUI=Urge Urinary Incontinence, SD=Standard Deviation, PVR=Post Void Residual, M=Month) 
Table 3 - Urodynamic Changes.

\begin{tabular}{|c|c|c|c|c|}
\hline \multirow[t]{2}{*}{ Variables } & \multicolumn{3}{|c|}{ BoNTA 100} & \multirow{2}{*}{$\begin{array}{c}\text { BoNTA } 200 \\
\text { Mean(SD) } \\
\end{array}$} \\
\hline & $\mathrm{N}$ & Mean(SD) & $\mathrm{N}$ & \\
\hline \multicolumn{5}{|c|}{ Volume at first desire $(\mathrm{mL})$} \\
\hline Baseline & 40 & $200(35.73)$ & 40 & 199 (35.71) \\
\hline At $3 m$ & 40 & $318(59.62)^{\star}$ & 40 & $300.2(44.28)^{*}$ \\
\hline At $6 m$ & 39 & $309.2(58.14)^{*}$ & 40 & $295.5(40.86)^{*}$ \\
\hline At $9 \mathrm{~m}$ & 38 & $246.8(53.78)^{\star} \ddagger \Delta$ & 38 & $291.8(42.82)^{\star} \ddagger \#$ \\
\hline \multicolumn{5}{|c|}{ Volume at strong desire $(\mathrm{mL})$} \\
\hline Baseline & 40 & $259(64.40)$ & 40 & $260.5(63.08)$ \\
\hline At $3 m$ & 40 & $427.5(58.78)^{\star}$ & 40 & $407.2(41.44)^{*}$ \\
\hline At $6 m$ & 39 & $417.9(51.2)^{\star}$ & 40 & $401.2(38.35)^{\star}$ \\
\hline At $9 \mathrm{~m}$ & 38 & $313.1(67.38)^{\star} \ddagger \Delta$ & 38 & $392.1(37.28)^{*} \ddagger \#$ \\
\hline \multicolumn{5}{|c|}{ Detrusor pressure (cm H2O) } \\
\hline Baseline & 40 & $27.8(10.12)$ & 40 & $30.6(11.09)$ \\
\hline At $3 m$ & 40 & $11.1(6.317)^{\star}$ & 40 & $9.25(3.01)^{*}$ \\
\hline At $6 m$ & 39 & $10.6(5.36)^{\star}$ & 40 & $9.07(3.22)^{*}$ \\
\hline At $9 \mathrm{~m}$ & 38 & $19.2(7.78)^{\star} \ddagger \Delta$ & 38 & $10.42(3.97)^{\star} \#$ \\
\hline \multicolumn{5}{|l|}{$\operatorname{MCC}(\mathrm{mL})$} \\
\hline Baseline & 40 & $277.7(75.29)$ & 40 & $289.2(70.83)$ \\
\hline At $3 m$ & 40 & $439(55.22)^{*}$ & 40 & $439(41.24)^{*}$ \\
\hline At $6 m$ & 39 & $437.4(55.36)^{\star}$ & 40 & $438.2(40.99)^{\star}$ \\
\hline At $9 \mathrm{~m}$ & 38 & $350(69.08)^{\star} \ddagger \Delta$ & 38 & $430.5(34.24)^{\star} \#$ \\
\hline
\end{tabular}

*significant in intragrou

p comparison to "before intervention"

$\ddagger$ significant in intragroup comparison to "3 months later"

$\Delta$ significant in intragroup comparison to "6 months later"

\# significant in intergroup comparison.

(Paired "t" test was the test of significance)

(MCC= Maximum Cystometric Capacity, N=Number of patients, SD=Standard Deviation, M=Month)

tric capacity and detrusor pressure improved significantly $(\mathrm{p}<0.001)$ in both groups. The mean values of urodynamic data at month 9 were significantly ameliorated $(p<0.001)$ compared to data at months 3 and 6 in group I.

However, in group II, the mean volume at first desire and at strong desire were significantly ameliorated $(\mathrm{p}<0.001)$ compared to data at month 3 only (Table 4$)$.

\section{Side effects}

Early postoperative hematuria was observed in 6 (4 women and 2 men) patients in group I and 9 (6 women and 3 men) patients in group II. During follow-up dysuria was observed in 6 (5 women and 1 male) and 15 (12 women and 3 men) patients in group I and II respectively. UTI was detected in 3 ( 2 women and 1 male) and 7 ( 5 women and 2 men) patients in group I and II respectively. 
Table 4 - OABSS and QOL Changes.

\begin{tabular}{|c|c|c|c|c|}
\hline \multirow[t]{2}{*}{ Variables } & \multicolumn{3}{|c|}{ BoNTA 100} & \multirow{2}{*}{$\begin{array}{c}\text { BoNTA } 200 \\
\text { Mean(SD) }\end{array}$} \\
\hline & $\mathrm{N}$ & Mean(SD) & $\mathrm{N}$ & \\
\hline \multicolumn{5}{|l|}{ OABSS } \\
\hline Baseline & 40 & $8.85(2.166)$ & 40 & 9.35 (1.994) \\
\hline At $1 \mathrm{~m}$ & 40 & $2.85(2.537)^{\star}$ & 40 & $3.32(2.092)^{*}$ \\
\hline At $3 m$ & 40 & $2.27(2.391)^{*} \dagger$ & 40 & $2.55(2.417)^{\star} \dagger$ \\
\hline At $6 \mathrm{~m}$ & 39 & $2.28(2.361)^{\star} \dagger$ & 40 & $2.37(2.518)^{*} \dagger$ \\
\hline At $9 m$ & 38 & $5.3(2.11)^{\star} \dagger \ddagger \Delta$ & 38 & $2.6(2.307)^{\star} \dagger \#$ \\
\hline \multicolumn{5}{|l|}{ QoL } \\
\hline Baseline & 40 & $42.7(8.58)$ & 40 & $40.8(6.82)$ \\
\hline At $1 \mathrm{~m}$ & 40 & $83.6(7.54)^{\star}$ & 40 & $82.8(7.60)^{*}$ \\
\hline At $3 m$ & 40 & $72.4(16.45)^{*} \dagger$ & 40 & $77.3(11.67)^{\star} \dagger$ \\
\hline At $6 m$ & 39 & $73.4(12.21)^{\star} \dagger$ & 40 & $77.3(10.12)^{\star} \dagger$ \\
\hline At $9 \mathrm{~m}$ & 38 & $68.5(7.57)^{\star} \dagger \Delta$ & 38 & $77.1(10.00)^{\star} \dagger \#$ \\
\hline
\end{tabular}

*significant in intragroup comparison to "before intervention"

tsignificant in comparison to "1 month later

fsignificant in intragroup comparison to "3 months later"

Äsignificant in intragroup comparison to "6 months later"

\#significant in intergroup comparison.

(Paired "t" test was the test of significance)

( $N=$ Number of patients, $S D=S t a n d a r d$ Deviation, M=Month, OABSS=Over Active Bladder Symptom Score, QoL=Quality of Life)

\section{DISCUSSION}

Sacral neuromodulation or surgical bladder augmentation were the available options for treatment of IOAB, however they are highly invasive and have long term complications (10). A European consensus group gave a grade A recommendation for BoNTA use in IDO (4) and a recent systematic review suggested that its use for refractory $\mathrm{OAB}$ is well justified (11).

In relation to the aforementioned results, the current study showed significant improvement in all clinical symptoms (frequency, nocturia, urgency and UUI) after BoNTA treatment. We observed no significant difference between $100 \mathrm{U}$ and $200 \mathrm{U}$ at post injection at months 1, 3 and 6 . The 200 U BoNTA dosage demonstrated consistent improvements till the end of the study and the significant difference between the study groups was observed at month 9 after injection. However, there was a significant amelioration at month 9 when compared to those at months 1, 3 and 6 in patients who received $100 \mathrm{U}$ except for nocturia. The response rate and the incidence of side effects of BoNTA on IOAB are closely related to the dose (12).

Many investigators reduced the dose of BoNTA to $100 \mathrm{U}$ and a satisfactory outcome can still be achieved for IDO due to the high incidence of side effects after BoNTA injections $(7,11,13-$ 15). The continence and the cure rate were respectively $22.9 \%$ and $15 \%$ by Nitti et al. (16), in the series by Visco et al. (17) the cure rate was 27\%. In other studies detrusor injections of $200 \mathrm{U}$ yielded long response duration of 12-15 months (12). Brubaker et al. (18) reported a mean duration of efficacy of 370 days of BoNTA $200 \mathrm{U}$.

The efficacy of a single injection of BoNTA toxin over 6 months and the literature supported $200 \mathrm{U}$ as the dose most likely to provide this durability (19-22). Regarding the changes in the urodynamic parameters after BoNTA injection, we 
found that the bladder capacity returned gradually, however the maximum effect on significant increase in cystometric capacity was observed at month 3 after treatment in both groups. Although BoNTA remained therapeutically effective up to 6 months, the effect reduced significantly in group I with time till the end of the study.

Doses ranging from $50 \mathrm{U}$ to $300 \mathrm{U}$ showed significantly greater improvement in symptoms of frequency, urgency, and UI as well as in urodynamic measures in the active-treatment arms with BoNTA doses of at least $100 \mathrm{U}(18,19,23)$. Regarding the optimal BoNTA dose, one study suggested minimal added benefit above $150 \mathrm{U},(19)$ and a Class III study comparing $100 \mathrm{U}$ vs. $150 \mathrm{U}$ failed to demonstrate any differences between the two doses (14).

The number of adverse events was lower than the one observed by others. In this study, none of the patients developed urinary retention or significant elevation of post-void residual urine (PVR>100 mL) following injection. Many studies of BoNTA for ID0 reported a 24-43\% incidence of transient urinary retention requiring CIC and also reported a 32-72\% incidence of a large PVR and difficulty in urination (24-28). Although a large PVR and chronic urinary retention remain obstacles for the wide use of BoNTA in treatment of refractory D0, no factors predicting these adverse effects have been found (7). Bauer et al. (29) have specifically looked at adverse events after injection of $100 \mathrm{U}, 200 \mathrm{U}$ and $500 \mathrm{U}$ of BoNTA by using a patient questionnaire, but he concluded the higher doses of the toxin led to higher rates of adverse events.

We observed mild hematuria which was procedural related and resolved conservatively. In the series by Kuo et al. (22) the hematuria was up to $7.8 \%$ and $3.6 \%$ in the series by Chapple et al. (15). In the current study, dysuria was increased in group II. Previous studies also reported dysuria in 5.8\% (15), 4\% (30) of patients that received $100 \mathrm{U}$ whereas; it was 33\% for $200 \mathrm{U}$ (31). On the other hand, many series did not notice this adverse effect $(12,14,18,20,26,27)$.

This study revealed more cases of UTI in group II; all cases received proper antibiotics and analgesics, which was comparable with others in which the rate of UTI ranged from 13\% to 44\% $(14,15,18,22,23,32)$ and this was related to clean intermittent self catheterization (CISC).

Our study is not without weaknesses; firstly, this study was done without a control arm. Secondly, it still represents a small number of patients. Finally, from the previous data we claim that further studies will be needed to confirm the effectiveness of $100 \mathrm{U}$ and $200 \mathrm{U}$ doses. They might also consider evaluating the efficacy and tolerability of repeated injections of BoNTA to optimize the risk-benefit ratio. This would help to introduce BoNTA as a treatment of choice in patients with refractory IOAB.

\section{CONCLUSIONS}

A single-injection procedure of $100 \mathrm{U}$ or $200 \mathrm{U}$ BoNTA is an effective and safe treatment for patients with IOAB who failed anticholinergic regimens. Following the procedure, OABSS and QoL were improved for 6 months; $100 \mathrm{U}$ injections seemed to have comparable results with $200 \mathrm{U}$. At month 9 there was a significant difference towards $200 \mathrm{U}$ with more incidence of adverse events.

\section{ACKNOWLEDGEMENTS}

The authors are grateful to the residents in Urology Department, Benha University Hospital, Benha, Egypt for the help in patients' recruitment and follow-up.

\section{CONFLICT OF INTEREST}

None declared.

\section{REFERENCES}

1. Abrams P, Cardozo L, Fall M, Griffiths D, Rosier P, Ulmsten $\mathrm{U}$, et al. Standardisation Sub-Committee of the International Continence Society. The standardisation of terminology in lower urinary tract function: report from the standardisation sub-committee of the International Continence Society. Urology. 2003;61:37-49.

2. Chancellor MB, Elovic E, Esquenazi A, Naumann M, Segal $\mathrm{KR}$, Schiavo G, et al. Evidence-based review and assessment of botulinum neurotoxin for the treatment of urologic conditions. Toxicon. 2013;67:129-40. 
3. Chapple CR, Khullar V, Gabriel Z, Muston D, Bitoun CE, Weinstein $D$. The effects of antimuscarinic treatments in overactive bladder: an update of a systematic review and meta-analysis. Eur Urol. 2008;54:543-62.

4. Apostolidis A, Dasgupta P, Denys P, Elneil S, Fowler CJ, Giannantoni A, et al. European Consensus Panel. Recommendations on the use of botulinum toxin in the treatment of lower urinary tract disorders and pelvic floor dysfunctions: a European consensus report. Eur Urol. 2009;55:100-19.

5. Chuang YC, Kuo HC, Chancellor MB. Botulinum toxin for the lower urinary tract. BJU Int. 2010;105:1046-58.

6. Denys P, Le Normand L, Ghout I, Costa P, Chartier-Kastler E, Grise P, et al. VESITOX study group in France. Efficacy and safety of low doses of onabotulinumtoxinA for the treatment of refractory idiopathic overactive bladder: a multicentre, doubleblind, randomised, placebo-controlled dose-ranging study. Eur Urol. 2012;61:520-9.

7. Kuo HC. Intravesical Botulinum Toxin Injection for Overactive bladder- What We Can Learn from Previous Clinical Trials. TZU CHI MED J. 2009; 21:277-84.

8. Homma Y, Yoshida M, Seki N, Yokoyama 0, Kakizaki H, Gotoh $\mathrm{M}$, et al. Symptom assessment tool for overactive bladder syndrome--overactive bladder symptom score. Urology. 2006;68:318-23.

9. EuroQol Group. EuroQol--a new facility for the measurement of health-related quality of life. Health Policy. 1990;16:199-208.

10. Hohenfellner M, Dahms SE, Matzel K, Thüroff JW. Sacral neuromodulation for treatment of lower urinary tract dysfunction. BJU Int. 2000;85,3:10-9; discussion 22-3

11. Mangera A, Andersson KE, Apostolidis A, Chapple C, Dasgupta $\mathrm{P}$, Giannantoni A, et al. Contemporary management of lower urinary tract disease with botulinum toxin $A$ : a systematic review of botox (onabotulinumtoxinA) and dysport (abobotulinumtoxinA). Eur Urol. 2011;60:784-95.

12. Sahai A, Sangster P, Kalsi V, Khan MS, Fowler CJ, Dasgupta P. Assessment of urodynamic and detrusor contractility variables in patients with overactive bladder syndrome treated with botulinum toxin-A: is incomplete bladder emptying predictable? BJU Int. 2009;103:630-4.

13. Jeffery S, Fynes M, Lee F, Wang K, Williams L, Morley R. Efficacy and complications of intradetrusor injection with botulinum toxin $A$ in patients with refractory idiopathic detrusor overactivity. BJU Int. 2007;100:1302-6.

14. Cohen BL, Barboglio P, Rodriguez D, Gousse AE. Preliminary results of a dose-finding study for botulinum toxin-A in patients with idiopathic overactive bladder: 100 versus 150 units. Neurourol Urodyn. 2009;28:205-8.

15. Chapple C, Sievert KD, MacDiarmid S, Khullar V, Radziszewski $\mathrm{P}$, Nardo $\mathrm{C}$, et al. OnabotulinumtoxinA $100 \mathrm{U}$ significantly improves all idiopathic overactive bladder symptoms and quality of life in patients with overactive bladder and urinary incontinence: a randomised, double-blind, placebo-controlled trial. Eur Urol. 2013;64:249-56.

16. Nitti VW, Dmochowski R, Herschorn S, Sand P, Thompson C, Nardo C, et al. EMBARK Study Group. OnabotulinumtoxinA for the treatment of patients with overactive bladder and urinary incontinence: results of a phase 3, randomized, placebo controlled trial. J Urol. 2013;189:2186-93.

17. Visco AG, Brubaker L, Richter HE, Nygaard I, Paraiso MF, Menefee SA, et al. Pelvic Floor Disorders Network. Anticholinergic therapy vs. Onabotulinumtoxina for urgency urinary incontinence. N Engl J Med. 2012;367:1803-13.

18. Brubaker L, Richter HE, Visco A, Mahajan S, Nygaard I, Braun TM, et al. Pelvic Floor Disorders Network. Refractory idiopathic urge urinary incontinence and botulinum A injection. J Urol. 2008;180:217-22.

19. Dmochowski R, Chapple C, Nitti VW, Chancellor M, Everaert K, Thompson C, et al. Efficacy and safety of onabotulinumtoxinA for idiopathic overactive bladder: a double-blind, placebo controlled, randomized, dose ranging trial. J Urol. 2010;184:2416-22.

20. White WM, Pickens RB, Doggweiler R, Klein FA. Short-term efficacy of botulinum toxin a for refractory overactive bladder in the elderly population. J Urol. 2008;180:2522-6.

21. Tincello DG, Kenyon S, Abrams KR, Mayne C, Toozs-Hobson P, Taylor D, et al. Botulinum toxin a versus placebo for refractory detrusor overactivity in women: a randomised blinded placebocontrolled trial of 240 women (the RELAX study). Eur Urol. 2012;62:507-14.

22. Kuo HC, Liao CH, Chung SD. Adverse events of intravesical botulinum toxin a injections for idiopathic detrusor overactivity: risk factors and influence on treatment outcome. Eur Urol. 2010;58:919-26.

23. Sahai A, Khan MS, Dasgupta P. Efficacy of botulinum toxin-A for treating idiopathic detrusor overactivity: results from a single center, randomized, double-blind, placebo controlled trial. J Urol. 2007;177:2231-6.

24. Kessler TM, Danuser H, Schumacher M, Studer UE, Burkhard FC. Botulinum A toxin injections into the detrusor: an effective treatment in idiopathic and neurogenic detrusor overactivity? Neurourol Urodyn. 2005;24:231-6.

25. Kuo HC. Will suburothelial injection of small dose of botulinum A toxin have similar therapeutic effects and less adverse events for refractory detrusor overactivity? Urology. 2006;68:993-7; discussion 997-8.

26. Khan S, Kessler TM, Apostolidis A, Kalsi V, Panicker J, Roosen $A$, et al. What a patient with refractory idiopathic detrusor overactivity should know about botulinum neurotoxin type a injection. J Urol. 2009;181:1773-8.

27. Kessler TM, Khan S, Panicker J, Roosen A, Elneil S, Fowler CJ. Clean intermittent self-catheterization after botulinum neurotoxin type A injections: short-term effect on quality of life. Obstet Gynecol. 2009;113:1046-51. 
28. Popat R, Apostolidis A, Kalsi V, Gonzales G, Fowler CJ, Dasgupta P. A comparison between the response of patients with idiopathic detrusor overactivity and neurogenic detrusor overactivity to the first intradetrusor injection of botulinum-A toxin. J Urol. 2005;174:984-9.

29. Bauer RM, Gratzke C, Roosen A, Hocaoglu Y, Mayer ME, Buchner A, et al. Patient-reported side effects of intradetrusor botulinum toxin type a for idiopathic overactive bladder syndrome. Urol Int. 2011;86:68-72.

30. Werner M, Schmid DM, Schüssler B. Efficacy of botulinum-A toxin in the treatment of detrusor overactivity incontinence: a prospective nonrandomized study. Am J Obstet Gynecol. 2005;192:1735-40.
31. Kuo HC. Urodynamic evidence of effectiveness of botulinum A toxin injection in treatment of detrusor overactivity refractory to anticholinergic agents. Urology. 2004;63:868-72.

32. Flynn MK, Amundsen CL, Perevich M, Liu F, Webster GD. Outcome of a randomized, double-blind, placebo controlled trial of botulinum A toxin for refractory overactive bladder. $J$ Urol. 2009;181:2608-15.

Correspondence address: Hammouda Sherif, MD Urology department, Faculty of Medicine, Benha University, Egypt 10 Elashraf Street, Benha Elgdeeda, Benha, Egypt Fax: +2 013 322-0100 E-mail: hammoda_elsherif@yahoo.com 